\title{
Targeting of Survivin Pathways by YM155 Inhibits Cell Death and Invasion in Oral Squamous Cell Carcinoma Cells
}

\author{
Wei Zhang ${ }^{\mathrm{a}}$ Yuan Liu ${ }^{\mathrm{b}}$ Yu Feng Lic Yun Yue ${ }^{\mathrm{b}, \mathrm{d}} \quad$ Xinghua Yang ${ }^{\mathrm{a}, \mathrm{e}} \quad$ Lin Peng $^{\mathrm{a}, \mathrm{d}}$ \\ aDepartment of Head and neck surgery, Linyi Tumour Hospital, Linyi, ${ }^{b}$ Department of radiotherapy, Linyi \\ Tumour Hospital, Linyi, 'Department of Oncology, People's hospital Of Zhangqiu, Jinan, 'Department of \\ School of Basic Medical Sciences, Taishan Medical University, Tai'an, eDepartment of School of dentistry \\ and oral health, Taishan Medical University, Tai'an, China
}

\section{Key Words}

Oral squamous cell carcinoma • Metastasis • Apoptosis • Survivin • NF- $\kappa B$

\begin{abstract}
Background/Aims: Specific overexpression in cancer cells and evidence of oncogenic functions make Survivin an attractive target in cancer therapy. The small molecule compound YM155 has been described as the first "Survivin suppressant" but molecular mechanisms involved in its biological activity and its clinical potential remain obscure. Survivin protein plays critical roles in oral squamous cell carcinoma (OSCC), suggesting that YM155 would be extremely valuable for OSCC. In this study, we tested our hypothesis whether YM155 could be an effective inhibitor of cell growth, invasion and angiogenesis in oral squamous cell carcinoma (OSCC) cells. Methods: SCC9 and SCC25 were treated with different concentration of YM155 for indicated time. Using MTT assay and flow cytometry analysis to detect cell growth and apoptosis; Using transwell and Wound healing assay to detect migration and invasion; Using reverse transcription-PCR, Western blotting and electrophoretic mobility shift assay for measuring gene and protein expression, and DNA binding activity of NF- $\mathrm{kB}$. Results: YM155 inhibited survivin-rich expressed SCC9 cell growth in a dose- and time dependent manner. This was accompanied by increased apoptosis and concomitant attenuation of NF$\kappa B$ and downregulation of NF-KB downstream genes MMP-9, resulting in the inhibition of SCC9 cell migration and invasion in vitro and caused antitumor activity and anti metastasis in vivo. YM155 treatment did not affect cell growth, apoptosis and invasion of surviving-poor expressed SCC25 cells in vitro. Conclusions: YM155 is a potent inhibitor of progression of SCC9 cells, which could be due to attenuation of survivin signaling processes. Our findings provide evidence showing that YM155 could act as a small molecule survivin inhibitor on survivin-rich expressed SCC9 cells in culture as well as when grown as tumor in a xenograft model. We also suggest that survivin could be further developed as a potential therapeutic agent for the treatment of survivin-rich expressed OSCC.




\section{Cellular Physiology Cell Physiol Biochem 2016;38:2426-2437 \\ and Biochemistry Published online: June 13, $2016 \quad \begin{aligned} & \text { DOI: 10.1159/000445594 } 2016 \text { The Author(s). Published by S. Karger AG, Basel } \\ & \text { www.karger.com/cpb }\end{aligned}$ \\ Zhang et al.: Effect of YM155 on Oral Squamous Cell Carcinoma}

\section{Introduction}

Squamous cell carcinoma is the most common malignant neoplasm of the oral cavity. The most important prognostic indicator for patients with oral squamous cell carcinoma (OSCC) is metastasis to cervical lymph nodes or distant organs [1].The process of metastasis consists of sequential and selective steps including proliferation, induction of angiogenesis, detachment, motility, invasion into circulation, aggregation and survival in the circulation, cell arrest in distant capillary beds, and extravasation into organ parenchyma [2]. The development of a metastasis depends on interplay between host factors and intrinsic characteristics of cancer cells, and the metastatic lesion represents the end point of many destructive events that only a few cells can survive [3,4]. Moreover, neoplasms contain a variety of subpopulations of cells with differing metastatic potential, and highly metastatic clones may exist within a primary tumor [4].

Survivin is an inhibitor of apoptosis protein (IAP) and is overexpressed in a wide spectrum of tumors including OSCC [5-7]. Its primary functions comprise inhibiting apoptosis and regulating mitosis, which are associated with metastasis and carcinogenesis [8-11]. YM155, a novel small-molecule surviving suppressant, selectively suppresses surviving expression, resulting in the induction of apoptosis and invasion inhibition in various malignancies [1216]. Furthermore, treatment with YM155 did not affecting normal tissues [13]. In clinical settings, YM155 was shown to be tolerable in phase I studies with advanced cancer patients and showed antitumor activity in NHL and HRPC subjects $[17,18]$. Multicenter phase II trials showed the safety and tolerability of YM155 in patients with unresectable melanoma [17] and advanced refractory NSCLC [18]. Although there has been rapid progress for elucidating the mechanism of action of YM155 as an antitumor agent, the exact mechanism has not yet been fully established. Previous study has reported that YM155 down-regulated survivin expression in NSCLC cells and increased the sensitivity of NSCLC cells to radiation. Inhibition of survivin expression by YM155 resulted in impaired DNA double-strand break repair and decreased S2056 autophosphorylation of DNA-PKcs in survivin-depleted cells [19].We investigated whether YM155-induced inhibition of OSCC cell growth could be attributed to survivin inhibition and its associated signaling, especially inactivation of nuclear factor- $\kappa \mathrm{B}$ (NF- $\kappa \mathrm{B}$ ) activity [20-22]. Moreover, since cell migration and invasion are important processes that are involved in tumor development and metastasis and because surviving signaling is known to control these processes [23, 24], we also examined the effect of YM155 on the processes of migration and invasion and angiogenesis of OSCC cells.

In the present study, we investigated the role and mechanism(s) by which YM155 may lead to the attenuation of NF- $\mathrm{KB}$, thereby inhibiting the growth of OSCC cells in vitro and in SCID xenograft model. We found that the inactivation of Survivin by YM155 down-regulated the NF- $\kappa B$ DNA-binding activity and its downstream gene MMP-9, resulting in the inhibition of OSCC cell growth, migration and invasion.

\section{Materials and Methods}

\section{Cell culture and reagents}

The study was conducted in accordance with the guidelines in the Declaration of Helsinki.The human OSCC cell lines SCC9, Cal27 and SCC25 were purchased from American Type Culture Collection (Shanghai, China). Cal27 were maintained in Dulbecco's Modified Eagle's Medium (DMEM) (Gibco, Grand Island, NY, USA), and SCC9 and SCC25 were maintained in DMEM-F12 (Gibco). All cell lines were supplemented with $10 \%$ fetal bovine serum and maintained at $37^{\circ} \mathrm{C}$ in a $5 \% \mathrm{CO}_{2}$ humidified incubator. Antibodies against Survivin,P65 and MMP-9 was purchased from R\&DSystems (Lille, France), antibodies against b-actin was from Santa Cruz (Shanghai, China).YM155 were purchased from Selleck Chemicals (Beijing, China); p65 siRNA were obtained from Santa Cruz Biotechnology (Santa Cruz, CA). NF-«Bp65 cDNA was kindly gifted by Dr. Din (General Hospital of Shenyang Military Region). Human OSCC SCC9 cells were transfected with 


\section{Cellular Physiology Cell Physiol Biochem 2016;38:2426-2437

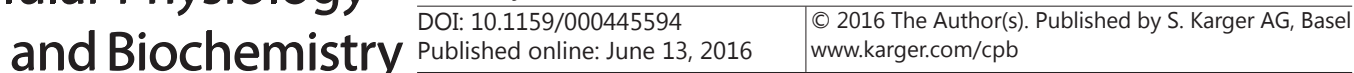 \\ Zhang et al.: Effect of YM155 on Oral Squamous Cell Carcinoma}

p65 siRNA and p65 cDNA, respectively, using Lipofectamine 2000. After $12 \mathrm{hr}$, the p65 transfected cells were treated with $50 \mathrm{nM}$ YM155 for 24-72 h. Then nuclear proteins were extracted. NF- $\mathrm{B}$ DNA-binding activity was measured by electrophoretic mobility shift assay (EMSA). Also, the apoptotic cells in the p65 transfected cells with different treatments were detected using FCM.

P65 siRNA and p65cDNA transfection

siRNA against p65 or p65cDNA (p65 overexpression) or negative control were transfected into SCC9 and SCC25 cells, using Lipofectamine 2000 reagent (Invitrogen) at the final concentration of $200 \mathrm{nM}$. After $48 \mathrm{~h}$ incubation, total RNA or cDNA was extracted and RT-PCR or western blot was performed.

\section{YM155 treatment}

SCC9 and SCC25 cells were treated with 5, 25 and 50 nM YM155 for 72 h or 50 nM YM155 for 24, 48 and $72 \mathrm{~h}$, then for further investigation with the treated cells. To study the signaling pathway, SCC9 and SCC25 cells were transfected with p65 siRNA or p65 cDNA 6 hours before 50 nM YM155 treatment for $72 \mathrm{~h}$. Then further investigation was performed below.

\section{Electrophoretic mobility-shift assay (EMSA)}

Nuclear proteins were extracted from cells or tumor tissues of mice using the nuclear extraction kit (Chemicon International, Temecula, CA, USA). The binding activity of NF- $\kappa \mathrm{B}$ was analyzed with Light Shift Chemiluminescent EMSA Kit (Pierce Biotechnology, Rockford, IL) according to the manufacturer's instructions.

The oligionucleotide sequence for NF- $\kappa$ B is AGTTGAGGGGACTTTCCCAGGC. The non-labeled fragment sequence is GCCTGGGAAAGTCCCCTCAACT. The experiments were repeated three times.

\section{Reverse Transcription-PCR}

TRIzol reagent was used to isolate RNA from the cells or tissues according to the manufacturer's instructions (Invitrogen). Total RNA $(1 \mu \mathrm{g})$ was then reverse-transcribed using the RevertAid First Strand cDNA synthesis kit (Fermentas) according to the manufacturer's instructions. The following primers were used: Survivin forward 5-ATGGGTGCCCCGACGTTGCC-3 and reverse 5-TCA ATC CAT GGC AGC CAGCT-3; p65: forward 5'-GCG AGA GGA GCA CAG ATACC-3' and reverse 5'-CTG ATA GCC TGC TCC AGGTC-3'; MMP9 forward 5'-CAA CAT CAC CTA TTG GATCC-3' and reverse 5'-CGG GTG TAG AGT CTC TCGCT-3', GAPDH, forward, 5'-CAT CTC TGC CCC CTC TGC TGA-3'; reverse, 5'-GGA TGA CCT TGC CCA CAG CCT-3'. All PCRs included GAPDH primers to quantify PCR products.

\section{Western blot analysis}

Cells were lysed and protein was analyzed by SDS-polyacrylamide gel electrophoresis (SDS-PAGE). The following antibodies were applied: monoclonal human anti-survivin, anti-p65, anti-MMP-9 and anti- $\beta$ actin Secondary antibodies (dilution 1:20,000) were horseradish peroxidase-conjugated (Beijing, China).

\section{ELISA for MMP-9}

SCC9 and SCC25 cells were incubated in serum-free medium supplemented with 5-50 nM YM155 for $72 \mathrm{~h}$. The cells were immediately centrifuged and preserved at $-80^{\circ} \mathrm{C}$ for subsequent assays. MMP-9 levels in supernatant of SCC9 were measured by ELISA according to the manufacturer's instructions.

\section{Apoptosis assay}

We used flow cytometry to determine apoptosis. SCC9 and SCC25 cells were cultured in 6-well plates overnight. Following distinct treatments, cells were harvested and washed with prechilled $4^{\circ} \mathrm{C}$ PBS twice, and centrifuged at $1500 \times \mathrm{g}$ for 5 minutes. After that, we discarded the supernatant and the pellet was resuspended gently in Annexin V-fluorescein isothiocyanate binding buffer and incubated with Annexin V-fluorescein isothiocyanate for 10 minutes in the dark at room temperature. Cells were centrifuged at $1500 \times g$ for 5 minutes, and the pellet was resuspended in binding buffer with PI in the dark at room temperature. Finally, the suspension of each group was analyzed by flow cytometry after filtration (300 apertures). 


\section{Cellular Physiology Cell Physiol Biochem 2016;38:2426-2437

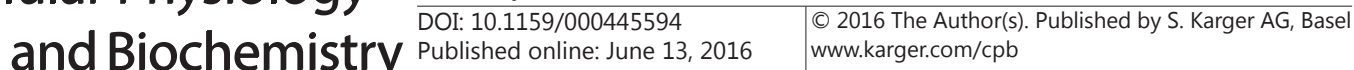 \\ Zhang et al.: Effect of YM155 on Oral Squamous Cell Carcinoma}

\section{Proliferation}

SCC9 and SCC25 cells were plated on 96-well plates with 500 cells per well, 6 parallel wells for each condition. On the next day, the medium was replaced with new medium (control medium with serum, medium with 5-50 nM YM155). The number of cells was measured after 1, 3 and 5 days of drug exposure with the MTT-assay (3-(4, 5-dimethylthiazol-2-yl)-2, 5-diphenyltetrazolium bromide, Sigma-Adrich). The MTT reagent was added to the wells at a final concentration $0.5 \mathrm{~g} / \mathrm{l}$. The cells were allowed to reduce MTT into formazan $\left(2 \mathrm{~h}\right.$ at $\left.37^{\circ} \mathrm{C}\right)$ the amount of which was measured spectrophotometrically at a wavelength of $550 \mathrm{~nm}$ against background (650 nm) after lysing the cells in DMSO.

\section{Invasion assay}

Cell invasion assays were conducted using 24-well Corning chambers coated with 1:10 serum-free DMEM diluted in matrigel. Briefly, SCC9 and SCC25 cells were seeded into upper inserts (30,000 cells per insert) in serum-free DMEM and treated with 5-50 nM for $48 \mathrm{~h}$. Outer wells were filled with $600 \mu \mathrm{l}$ DMEM containing 10\% FBS to act as the chemoattractant. Cells were allowed to migrate and invade for 24-48 $\mathrm{h}$, respectively. The invaded cells on the bottom face of the filter were fixed in $90 \%$ ice-cold ethanol and stained with $8 \%$ crystal violet. The entire membrane was photographed by light microscopy. Each assay was conducted in duplicate and repeated three times.

\section{Wound healing assay}

SCC9 and SCC25 cells (40,000 cells per well) were seeded in 24-well plates and treated with $50 \mathrm{Nm}$ YM for $48 \mathrm{~h}$. After formation of a complete monolayer, scratches were made within the monolayer using a standard 200- $\mu$ l plastic tip. Migration and cell movement throughout the wound area was observed under a phase-contrast microscope at the same spot after $24 \mathrm{~h}$. The percentage of filled wound area was calculated using the following equation: wound filled $(\%)=$ (original wound area - remaining wound area)/original wound area $\times 100$. Each assay was conducted in triplicate and repeated three times.

\section{In vivo antitumor and anti lung metastasis activities against SCC9 xenograft models}

5-week-old female nude were purchased from Animal Research Center of the Shandong University (Jinan, China) and maintained in a standard environment and maintained on standard diet and water under pathogen-free conditions throughout all experiments. SCC9 cells $\left(3 \times 10^{6}\right)$ cells were mixed with Matrigel and s.c. injected into the flanks of mice. After 3 week, tumor size reached approximately $80 \mathrm{~mm} 3-100 \mathrm{~mm}$, mice were randomly assigned to treatment and control groups. YM155 at $5 \mathrm{mg} / \mathrm{kg} / \mathrm{day}$ or vehicle control was administered subcutaneously as a 7-day continuous infusion using a micro-osmotic pump (Alzet model 1007D) implanted in the left dorsal flank under anesthesia. Tumor diameter were measured twice a week, and tumor volume was determined (length $\times$ width $^{2} / 2$ ). The xenograft tissues were collected immediately after the animals were sacrificed and stored at $-80^{\circ} \mathrm{C}$ for $\mathrm{H} \& \mathrm{E}$ histological examination of survivin, MMP-9 and NF-אBp65 detection. Mice were sacrificed, the lungs were fixed, paraffin embedded, cut, and stained with H\&E staining.The number of metastasis nodes in the lung surface was counted.

\section{Statistical analysis}

The significance of the results was determined by the Student's t test). Values are expressed as mean \pm SD from at least three separate experiments and $P$ value less than 0.05 was considered to be statistically significant.

\section{Results}

YM inhibits SCC9 cells growth

The baseline expression of Survivin protein and mRNA was detected by RT-PCR and Western blot in the SCC9, Cal27 and SCC25 cells. Survivin expressed the highest in the SCC9 cells and the least in SCC25 cells among the three cells (Fig. 1A and 1B). So we used SCC9 and SCC25 cells for further study. SCC9 and SCC25 cells were treated with YM155 at 5, 25 and $50 \mathrm{nM}$ for $72 \mathrm{~h}$, or $50 \mathrm{nM}$ YM155 for 24, 48 and $72 \mathrm{~h}$. Survivin protein was decreased in a dose- and time-dependent manner in the SCC9 cells (Fig. 1C and 1D). Survivin mRNA was 


\section{Cellular Physiology Cell Physiol Biochem 2016;38:2426-2437 and Biochemistry \begin{tabular}{c|c} 
DOI: 10.1159/000445594 & $\begin{array}{l}\text { O 2016 The Author(s). Published by S. Karger AG, Basel } \\
\text { wwww.karger.com/cpb }\end{array}$
\end{tabular}

Fig. 1. Effect of YM155 on Survivin expression. (A) Survivin protein was detected by Western blot in the SCC9, Cal27 and SCC25 cells. (B) Survivin mRNA was detected by RT-PCR in the SCC9, Cal27 and SCC25 cells. (C, D) SCC9 cells were treated with YM155 at 5, 25 and $50 \mathrm{nM}$ for 72 h, or 50 nM YM155 for 24, 48 and $72 \mathrm{~h}$. Survivin mRNA was detected by RT-PCR in the SCC9 cells. (E, F) SCC9 cells were treated with YM155 at 5, 25 and $50 \mathrm{nM}$ for $72 \mathrm{~h}$, or $50 \mathrm{nM}$ YM155 for 24,

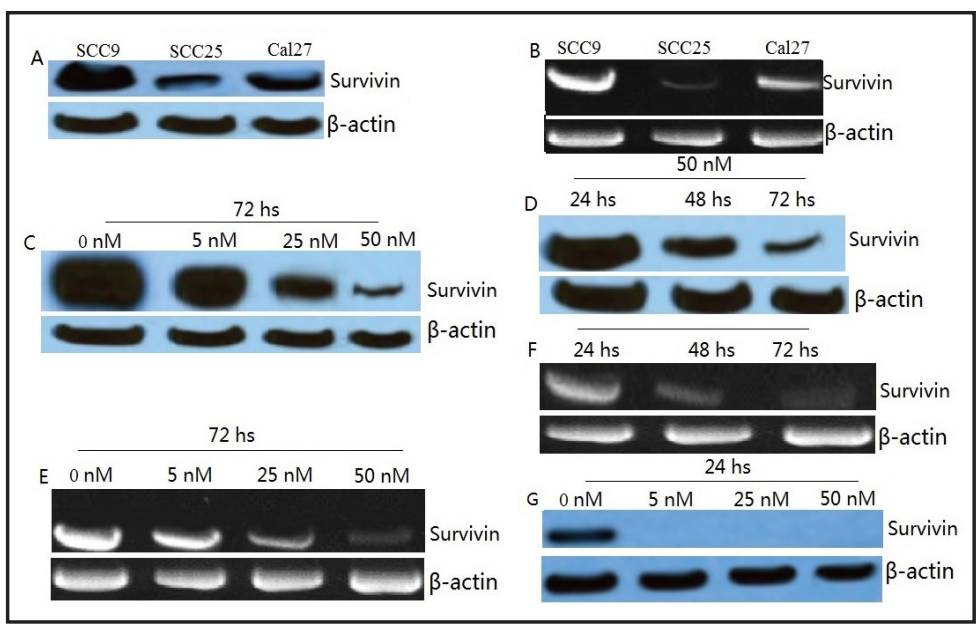
48 and $72 \mathrm{~h}$. Survivin mRNA was detected by western blot assay in the SCC9 cells. (G) SCC25 cells were treated with YM155 at 5, 25 and $50 \mathrm{nM}$ for $24 \mathrm{~h}$. Survivin protein was detected by western blot assay.

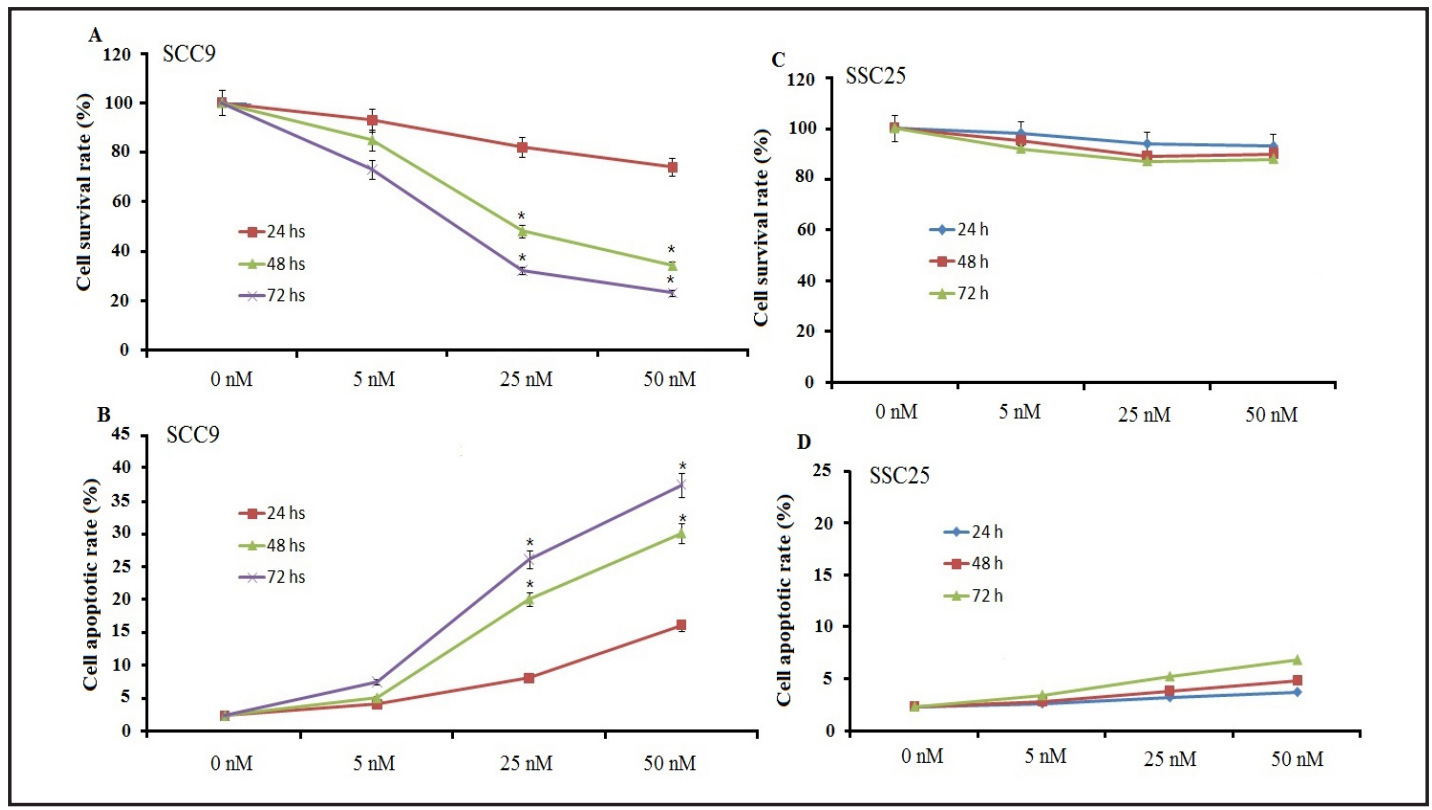

Fig. 2. YM155 induces apoptosis and inhibits growth of OSCC cells. SCC9 and SCC25 cells were treated with YM155 at indicated doses for 24-72 hours. (A, C) Cell survival rate was detected by MTT assay; (B, D) Apoptosis was determined by FACS analysis. The survival rate and apoptotic rates are the means \pm SD of 3 independent experiments ${ }^{*} \mathrm{P}<0.05$ compared with the control group.

also decreased in a dose- and time-dependent manner in the SCC9 cells (Fig. 1E and 1F). YM 155 resulted in cell growth inhibition in a dose- and time-dependent manner in the SCC9 cells (Fig. 2A).

In SCC2 5 cells, the baseline of Survivin mRNA expression was undetectable by RT-PCR assay (Fig. 1B).

So we only observed whether YM155 could inhibit survivin protein expression in SCC25 cells by western blot assay. The results showed that treatment with $5 \mathrm{nM}$ YM 155 for $24 \mathrm{~h}$ could completely inhibit the survivin expression in the SCC25 cells (Fig. 1G). In addition, treatment with 5, 25 and $50 \mathrm{nM}$ YM155 for 24-72 h only partly inhibit SCC25 cell growth, but there was no statistical significance compared to the controls(Fig. 2C), suggesting that 


\section{Cellular Physiology Cell Physiol Biochem 2016;38:2426-2437 \begin{tabular}{l|l} 
and Biochemistry Published online: June 13,2016 & $\begin{array}{l}\text { C } 2016 \text { The Author(s). Published by S. Karger AG, Basel } \\
\text { www.karger.com/cpb }\end{array}$
\end{tabular}

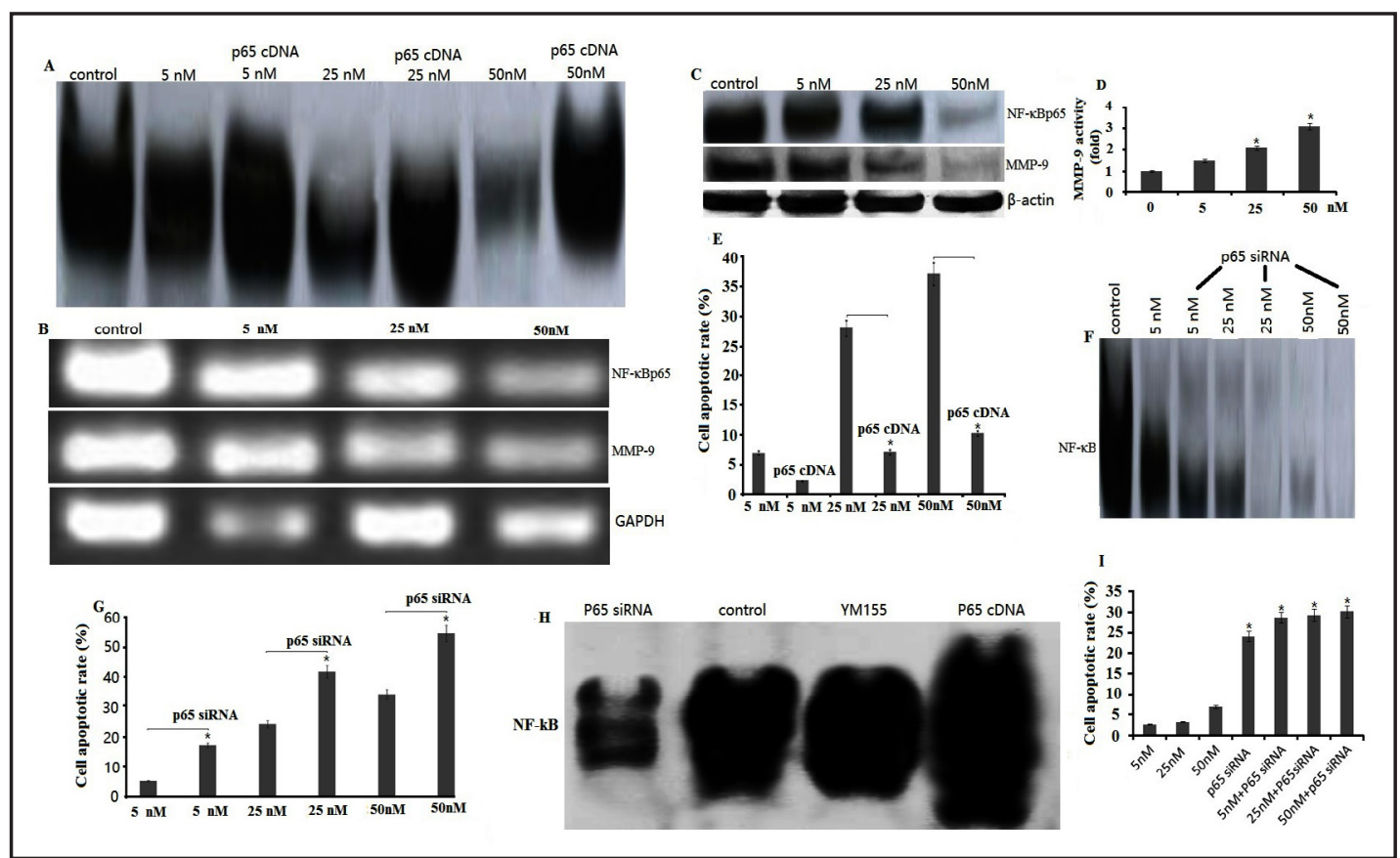

Fig. 3. YM155 triggers intrinsic and extrinsic apoptotic pathways. (A) Effect of YM155 treatment or/and p65 cDNA transfection on the NF- $\kappa B$ DNA-binding activity in SCC9 cells. (B, C) YM155-treated SCC9 cells were subjected to analysis NF- $\mathrm{B}$ p65 mRNA and MMP-9 mRNA, or NF- $\kappa$ B p65 A and MMP-9 protein by RT-PCR and western blot assay. (D) YM155-treated SCC9 cells were subjected to analysis MMP-9 activity by ELISA. (E) YM155 treatment or in combination with p65 cDNA transfection on cell apoptosis by FACS analysis. The survival rate and apoptotic rates are the means \pm SD of 3 independent experiments ${ }^{*} \mathrm{P}<0.05$ compared with the control group. (F) Effect of YM155 treatment or/and p65 siRNA transfection on the NF- $\kappa B$ DNA-binding activity in SCC9 cells. (G) YM155 treatment or in combination with p65 siRNA transfection on cell apoptosis by FACS analysis. The survival rate and apoptotic rates are the means \pm SD of 3 independent experiments ${ }^{*} \mathrm{P}<0.05$ compared with the control group. (H) Effect of YM155 treatment or/and p65 siRNA/p65 cDNA transfection on the NF- $\kappa$ B DNA-binding activity in SCC25 cells. (I) YM155 treatment or in combination with p65 siRNA transfection on SCC25 cell apoptosis by FACS analysis. The survival rate and apoptotic rates are the means \pm SD of 3 independent experiments ${ }^{*} \mathrm{P}<0.05$ compared with the YM155 treatment groups.

YM155 only inhibit cell growth in survivin-rich SCC9 cells. Next, we examined whether the inhibition of cell growth of YM155 was also accompanied by the induction of apoptosis.

YM155 induced apoptosis in SCC9 cells

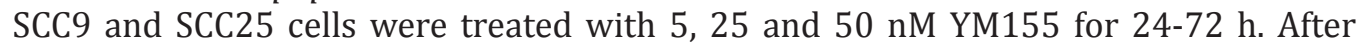
treatment, the cell apoptosis was measured by flow cytometry. The results showed that induction of apoptosis was found to be time and dose-dependent in SCC9 cells (Fig. 2B). In SCC25 cells, treatment with 5, 25 and $50 \mathrm{nM}$ YM155 for 24-72 h only induced fewer apoptotic cells, which had no statistical significance compared to the controls ( $p>0.05$; Fig. 2D). These results provided convincing data showing that YM155 could only induce apoptosis in survivin-rich SCC9 cells. To further understand the molecular mechanism involved in YM155induced apoptosis of SCC9 cells, alterations in the cell survival pathway were investigated.

YM155 inhibits NF- $\kappa B$ activation and NF- $\kappa B$-dependent MMP-9 expression and activity

Nuclear extracts from control and YM155-treated SCC9 and SCC25 cells were subjected to analysis for NF- $\kappa B$ DNA binding activity as measured by EMSA. We found that YM155 treatment significantly inhibited NF- $\kappa B$ DNA-binding activity in a dose- dependent manner compared to the control (Fig. 3A). These results indicated that YM155 decreases NF- $\kappa B$ DNAbinding activity in SCC9 cells. We next determined the expression of NF- $\kappa B$-dependent gene 


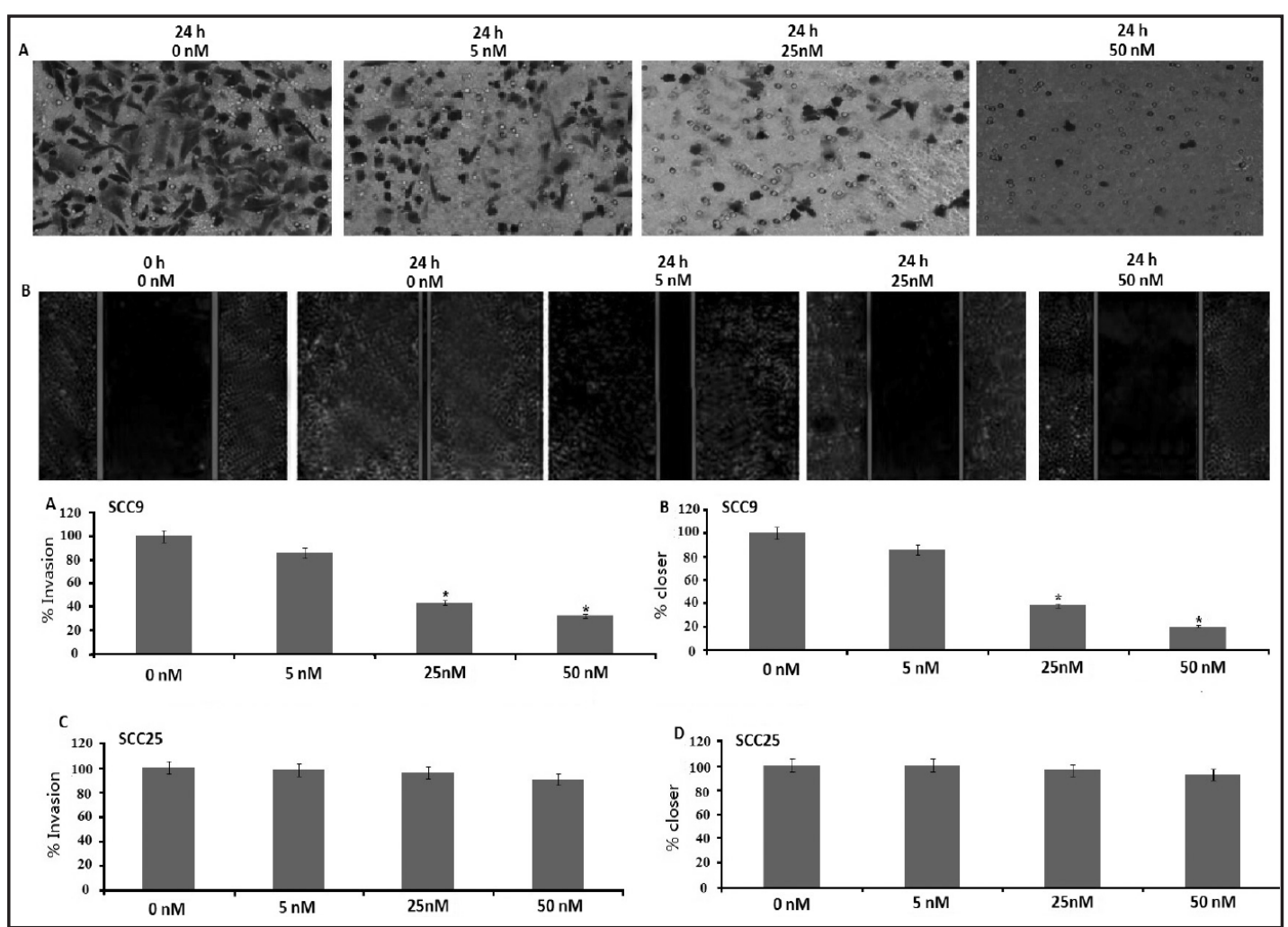

Fig. 4. Effect of YM155 on migration and invasion in SCC9 and SCC25 cells. (A, C) Cell migratory ability detected by Transwell migration assay. (B, D) Cell migratory ability detected by wound healing assay. Data is presented as the mean \pm SD; P values were calculated with the Student's t-test. ${ }^{*}<<0.05$.

product MMP-9. RT-PCR analysis showed that YM155 inhibited the expression of NF- $\kappa$ B p65 mRNA and MMP-9 mRNA genes in SCC9 cells (Fig. 3B). Western blot assay has the same results (Fig. 3C).ELISA assay showed that YM155 also inhibited MMP-9 activity in a doseand time-dependent manner compared to the control (Fig. 3D). Thought significant baseline activation of NF- $\kappa$ B in SCC25 cells, YM155 treatment did not affect NF- $\kappa$ B activity in SCC25 cells (Fig. 3H). In addition, YM155 treatment did not affect MMP-9 expression and activity in SCC25 cells (data not shown).

YM155 induces apoptosis of SCC9 cells through the NF-KB inactivation

We transfected NF- $\kappa B$ p65 cDNA or siRNA into SCC9 and SCC25 cells, then treated the transfected cells with $50 \mathrm{nM}$ YM155, and detected NF- $\mathrm{KB}$ DNA-binding activity and apoptosis. In SCC9 cells, we found that p65 cDNA transfection enhanced the NF- $\kappa B$ DNAbinding activity, and inhibited apoptosis in YM155-treated cells (Fig. 3A and 3E). In contrast, p65 siRNA transfection inhibited the activation of NF- $\kappa B$ and enhanced apoptosis induced by YM155 (Fig. 3F and 3G). Moreover, we found that YM155 treatment combined with p65 siRNA transfection exerted greater inhibitory effect on the activation of NF- $\kappa B$, resulting in a more pronounced effect on the induction of apoptosis (Fig. 3E and 3G).

In SCC25 cells, although p65 cDNA transfection enhanced the NF- $\kappa B$ DNA-binding activity in SCC25 cells, YM155 treatment did not increase or decrease cell apoptosis (Fig. 3I). In contrast, p65 siRNA transfection significantly inhibited the baseline activation of NF- $\mathrm{KB}$ followed by increased cell apoptosis (Fig. 3I). However, YM155 treatment did not affect p65 siRNA transfection-induced apoptosis (Fig. 3I). These results provide mechanistic support in favor of our claim that the apoptosis-inducing effect by YM155 is mediated through the inactivation of survivin/NF- $\kappa \mathrm{B}$ pathway. 


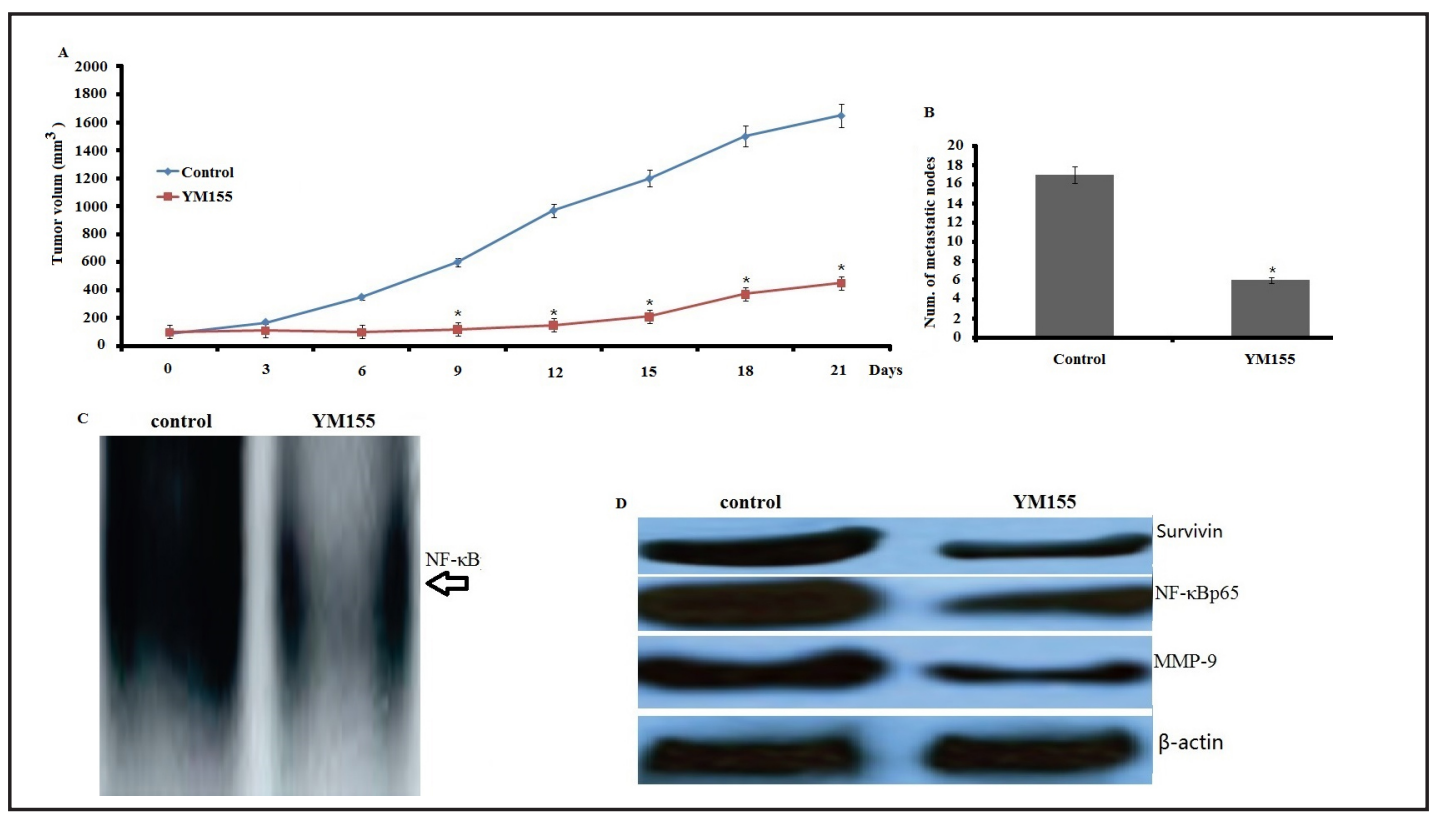

Fig. 5. YM155 inhibits xenograft growth and lung metastasis of OSCC. (A) Tumor xenografts were established by s.c. injection of SCC9 cells into the right flanks of the mice. When tumor size reached around 80 $\mathrm{mm}^{2}-100 \mathrm{~mm}^{2}$ (about 3 weeks) mice were administered with a 7-day YM155 continuous infusion using a micro-osmotic pump. Tumor size was measured every three days. The tumor growth curve was shown. *P $<0.05$ compared with the control group. (B) Fewer metastatic nodes were formed on the surface of lungs in the YM155 treated groups than the control group. p < 0.05 vs. control. (C) YM155 treatment inhibits the NF- $\kappa B$ activity in tumor tissues using EMSA. (D) YM155 treatment inhibits the expression of surviving, NFКBp65 and MMP-9 by western blot assay.

\section{YM155 inhibits SCC9 cells migration and invasion}

MMP-9 has been thought to be critically involved in the processes of tumor cell migration, invasion and metastasis. Because YM155 inhibited the expression and activity on MMP-9, we tested the effects of YM155 on cancer cell migration and invasion. We found that 5-50 nM YM decreased SCC9 cell migration (Fig. 4A). Moreover, by the wound-healing assay, we found that the area changes for wound-healing in the YM155 treated SCC9 cells were reduced compared with the untreated-SCC9 cells $(P<0.05)$ (Fig. 4B), suggesting that YM155 has a dose dependency effect on cancer cell migration and invasion. However, in SCC25 cells, YM155 treatment did not affect cell migration and invasion in vitro (Fig. 4C-D).

YM155 inhibits SCC9 cell tumor growth and lung metastasis in vivo

As shown in Fig. 5A, YM155 treatment for 3 weeks significantly inhibited tumor growth compared to untreated control ( $p<0.05$ vs. control). In addition, fewer metastatic nodes were formed on the surface of lungs in the YM155 treated groups than the control group (Fig. 5B, $p<0.05$ vs. control).We subsequently asked the most important question of whether the antitumor activity of YM155 could be correlated with changes in the biological markers that are known to be altered, as shown earlier in our in vitro studies.

To determine whether YM155 could affect the function of NF- $\mathrm{KB}$ in vivo, we examined the changes in NF- $\kappa B$ activity in tumor tissues using EMSA. EMSA with nuclear extracts from YM155-treated or vehicle-treated xenograft tumor tissues revealed that treatment with YM155 strongly inhibited the DNA-binding activity of NF- $\kappa B$ compared to untreated controls

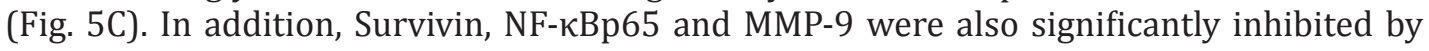
YM155 treatment by western blot assay (Fig. 5D). 


\section{Cellular Physiology Cell Physiol Biochem 2016;38:2426-2437 \\ \begin{tabular}{l|l} 
and Biochemistry Published online: June 13, 2016 & $\begin{array}{l}\text { (c) 2016 The Author(s). Published by S. Karger AG, Basel } \\
\text { www.karger.com/cpb }\end{array}$
\end{tabular} \\ Zhang et al.: Effect of YM155 on Oral Squamous Cell Carcinoma}

\section{Discussion}

YM155 was the first drug reported to block Survivin expression [12]. This small imidazolium compound was initially identified from a pharmacological screen based on BIRC5 promoter inhibition and described as a first in class "Survivin suppressant". YM155 has been demonstrated to exert antitumor activity, to suppress Survivin expression and to induce tumor cell apoptosis and inhibit cell metastasis, in various human cancer models $[13,14,16-18]$. Our current data show that YM155 not only inhibits cell growth but also induces apoptotic cell death of survivin-rich expressed SCC9 cells, a finding similar to those observed in Melanoma [25], renal Cell Carcinoma [26], multiple myeloma [27] and head neck squamous cell carcinoma [28, 29]. However, YM155 treatment did not affect growth and apoptosis of poor-survivin expressed SCC25 cells, suggesting YM155 could be a target for the treatment of survivin-rich expressed OSSC.

$\mathrm{NF}-\kappa \mathrm{B}$ is a group of dimeric transcription factors comprising members of the NF- $\mathrm{kB} /$ Rel family, including p50, p52, p65 (Rel-A), Rel-B, and c-Rel. Although p50 and p65 regulate the canonical NF- $\kappa B$ pathway, p52 and Rel-B are components of the noncanonical NF- $\kappa B$ pathway. The activity of NF- $\kappa B$ is normally kept in check by the I $\kappa B$ family of inhibitors, which bind to and sequester NF- $\mathrm{BB}$ in the cytoplasm [30]. Activation of NF- $\mathrm{KB}$ is triggered by IKB phosphorylation by IKK kinases and subsequent proteasomal degradation, which allows NF- $\kappa \mathrm{B}$ to translocate to the nucleus, where it binds to the $\kappa \mathrm{B}$ consensus sequences and modulates numerous target genes [31].

Many studies have shown NF- $\kappa$ B p65 has been described as an important therapeutic target in cancer, including OSCC [32-35].

In this study, we found that YM155 inhibited the p65 expression. To further investigate whether the enhanced cell growth inhibition and apoptosis by YM155 was mediated through the NF- $\kappa B$ pathway, we conducted NF- $\kappa$ B cDNA and NF- $\kappa$ B p 65 siRNA transfection studies. We found that p65 cDNA transfection induced the activity of NF- $\kappa$ B. However, NF- $\kappa B$ p 65 siRNA was functioning similarly as YM155, which inhibited NF- $\kappa B$ DNA-binding activity. Moreover, YM155 treatment combined with p65 siRNA transfection exerted greater inhibitory effect on the activation of NF- $\kappa \mathrm{B}$ and caused greater degree of apoptotic cell death, suggesting that YM155-induced cell growth inhibition and apoptosis is partly mediated through the NF-KB pathway. Importantly, we also found that YM155 could abrogate the activation of NF$\kappa \mathrm{B}$ induced by the p65 cDNA transfection. In the present study,we also found that although survivin is poor-expressed in the SCC25 cells, it has rich baseline NF- $\kappa B$ activity. p65 siRNA transfection inhibited the NF- $\kappa \mathrm{B}$ activity, followed by increased apoptosis and growth inhibition.YM155 treatment combined with p65 siRNA transfection did not increase or decrease apoptosis in SCC25 cells compared to the p65 siRNA transfection alone. Therefore, our results clearly show that YM155 inhibits cell proliferation and induces of apoptotic cell

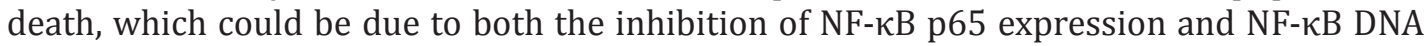
binding activity.

NF- $\kappa B$ activation has been reported to regulate MMP-9, which is directly associated with metastatic processes [36, 37]. Indeed, in this study, we showed that YM155 reduced NF- $\kappa B$ DNA binding activity and concomitantly inhibited the expression of MMP-9. We also found that YM155 inhibited the activity of MMP-9 in SCC9 cells. Since we observed that YM155 inhibited the expression and activities of MMP-9, we tested the effects of YM155 on the migration and invasion of SCC9 cells. We found that YM155 inhibited migration and invasion of SCC9 cells in vitro. In SCC25 cells, YM155 did not affect MMP-9 expression and activity as well as cell invasion, suggesting that YM155 has no effect on invasion of survivinpoor expressed SCC25 cells.

We next tested YM155 against SCC9 cells in a SCID xenograft model. Our results show that YM155 was effective in decreasing tumor volume and inhibiting lung metastasis compared to untreated animals. These results were consistent with inactivation of MMP-9, documenting that YM155 could inhibit cancer cell migration and invasion which is likely due in part through the downregulation of MMP-9, mediated by inactivation of NF- $\kappa B$. 


\section{Cellular Physiology Cell Physiol Biochem 2016;38:2426-2437 \begin{tabular}{ll|l} 
and Biochemistry & $\begin{array}{l}\text { DOI: 10.1159/000445594 } \\
\text { Published online: June 13,2016 }\end{array}$ & $\begin{array}{l}\text { C } 2016 \text { The Author(s). Published by S. Karger AG, Basel } \\
\text { www.karger.com/cpb }\end{array}$
\end{tabular} \\ Zhang et al.: Effect of YM155 on Oral Squamous Cell Carcinoma}

\section{Conclusion}

In summary, our study provides evidence that YM155 inhibits tumor growth, invasion and lung metastasis in Survivin-rich expressed SCC9 cells both in vitro and in vivo, but not in surviving-poor expressed SCC2 5 cells. Thus, we believe that YM155 could potentially be an effective therapeutic agent for the inactivation of NF- $\mathrm{KB}$ and its downstream target gene MMP-9, resulting in the inhibition of cell growth, invasion and metastasis of surviving-rich expressed OSCC. Our study suggests that YM155 should be developed for the treatment of urviving-rich expressed OSCC.

\section{Acknowledgements}

This study was granted from the National nature scientific research fund (No: 4113350025).

\section{Disclosure Statement}

No potential conflicts of interest were disclosed.

\section{References}

1 Marla V, Hegde V, Shrestha A: Relationship of Angiogenesis and Oral Squamous Cell Carcinoma. Kathmandu Univ Med J (KUMJ) 2015;13:178-185.

2 Liang L, Zhang T, Kong Q, Liang J, Liao G: A meta-analysis on selective versus comprehensive neck dissection in oral squamous cell carcinoma patients with clinically node-positive neck. Oral Oncol 2015;51:1076-1081.

3 Cheng YS, Rees T, Wright J: Updates Regarding Diagnostic Adjuncts for Oral Squamous Cell Carcinoma. Tex Dent J 2015;132:538-549.

4 Malik UU, Zarina S, Pennington SR: Oral squamous cell carcinoma: Key clinical questions, biomarker discovery, and the role of proteomics. Arch Oral Biol 2016;63:53-65.

5 Su L, Wang Y, Xiao M, Lin Y, Yu L: Up-regulation of survivin in oral squamous cell carcinoma correlates with poor prognosis and chemoresistance. Oral Surg 2010;110:484-491.

6 Khan Z, Tiwari RP, Mulherkar R, Sah NK, Prasad GB, Shrivastava BR, Bisen PS: Detection of survivin and p53 in human oral cancer: correlation with clinicopathologicfindings. Head Neck 2009;31:1039-1048.

7 Lin CY, Hung HC, Kuo RC, Chiang CP, Kuo MY:Survivin expression predicts poorer prognosis in patients with areca quid chewing-related oral squamous cell carcinoma in Taiwan. Oral Oncol 2005;41:645-654.

8 Khan S, Aspe JR, Asumen MG, Almaguel F, Odumosu O, Acevedo-Martinez S, De Leon M, Langridge WH, Wall NR: Extracellular, cell-permeable survivin inhibits apoptosis while promoting proliferative and metastatic potential. Br J Cancer 2009;100:1073-1082.

9 Bergamaschi A, Christensen BL, Katzenellenbogen BS: Reversal of endocrine resistance in breast cancer: interrelationships among 14-3-3ろ, FOXM1, and a gene signature associated with mitosis. Breast Cancer Res 2011;13:R70.

10 McKenzie JA, Grossman D: Role of the apoptotic and mitotic regulator survivin in melanoma. Anticancer Res 2012;32:397-404.

11 Hori M, Miki T, Okamoto M, Yazama F, Konishi H, Kaneko H, Shimamoto F, Ota T, Temme A, Tatsuka M:The detergent-soluble cytoplasmic pool of survivin suppresses anoikis and its expression is associated with metastatic disease of human colon cancer. PLoS One 2013;8:e55710.

12 Nakahara T, Kita A, Yamanaka K, Mori M, Amino N, Takeuchi M, Tominaga F, Hatakeyama S, Kinoyama I, Matsuhisa A, Kudoh M, Sasamata M: YM155, a novel small-molecule survivin suppressant, induces regression of established human hormone-refractory prostate tumor xenografts. Cancer Res 2007;67:8014-8021. 


\section{Cellular Physiology Cell Physiol Biochem 2016;38:2426-2437 \begin{tabular}{l|l} 
and Biochemistry Published online: June 13,2016 & $\begin{array}{l}\text { D) } 2016 \text { The Author(s). Published by S. Karger AG, Basel } \\
\text { www.karger.com/cpb }\end{array}$ \\
\hline
\end{tabular} \\ Zhang et al.: Effect of YM155 on Oral Squamous Cell Carcinoma}

13 Cheng XJ, Lin JC, Ding YF, Zhu L, Ye J, Tu SP: Survivin inhibitor YM155 suppresses gastric cancer xenograft growth in mice without affecting normal tissues. Oncotarget 2016;7:7096-7109.

14 Guo K, Huang P, Xu N, Xu P, Kaku H, Zheng S, Xu A, Matsuura E, Liu C, Kumon H: A combination of YM-155, a small molecule survivin inhibitor, and IL-2 potently suppresses renal cell carcinoma in murine model. Oncotarget 2015;6:21137-21147.

15 Mehta A, Zhang L, Boufraqech M, Liu-Chittenden Y, Zhang Y, Patel D, Davis S, Rosenberg A, Ylaya K, Aufforth R, Li Z, Shen M, Kebebew E: Inhibition of Survivin with YM155 Induces Durable Tumor Response in Anaplastic Thyroid Cancer. Clin Cancer Res 2015;21:4123-4132.

16 Zhang L, Zhang W, Wang YF, Liu B, Zhang WF, Zhao YF, Kulkarni AB, Sun ZJ:Dual induction of apoptotic and autophagic cell death by targeting survivin in head neck squamous cell carcinoma. Cell Death Dis 2015;6:e1771.

17 Tolcher AW, Mita A, Lewis LD, Garrett CR, Till E, Daud AI: Phase I and pharmacokinetic study of YM155, a small-molecule inhibitor of survivin. J Clin Oncol 2008;26:5198-5203.

18 Lewis KD, Samlowski W, Ward J, Catlett J, Cranmer L, Kirkwood J: A multi-center phase II evaluation of the small molecule surviving suppressor YM155 in patients with unresectable stage III or IV melanoma. Invest New Drugs 2011;29:161-166.

19 Hu S, Fu S, Xu X, Chen L, Xu J, Li B, Qu Y, Yu H, Lu S, Li W: The mechanism of radiosensitization by YM155, a novel small molecule inhibitor of survivin expression, is associated with DNA damage repair. Cell Physiol Biochem 2015;37:1219-1230.

20 Wang QP, Wang Y, Wang XD, Mo XM, Gu J, Lu ZY, Pan ZL, Zhu YX: Survivin up-regulates the expression of breast cancer resistance protein (BCRP) through attenuating the suppression of p53 on NF- $\kappa B$ expression in MCF-7/5-FU cells. Int J Biochem Cell Biol 2013;45:2036-2044.

21 Wang K, Brems JJ, Gamelli RL, Holterman AX: Survivin signaling is regulated through nuclear factorkappa B pathway during glycochenodeoxycholate-induced hepatocyte apoptosis. Biochim Biophys Acta 2010;1803:1368-1375.

22 Véquaud E, Séveno C, Loussouarn D, Engelhart L, Campone M, Juin P, Barillé-Nion S: YM155 potently triggers cell death in breast cancer cells through an autophagy-NF- $\mathrm{B}$ network. Oncotarget 2015;6:1347613486.

23 Fest S, Huebener N, Bleeke M, Durmus T, Stermann A, Woehler A, Baykan B, Zenclussen AC, Michalsky E, Jaeger IS, Preissner R, Hohn O, Weixler S, Gaedicke G, Lode HN: Survivin minigene DNA vaccination is effective against neuroblastoma. Int J Cancer 2009;125:104-114.

24 Xiang R, Luo Y, Niethammer AG, Reisfeld RA:Oral DNA vaccines target the tumor vasculature and microenvironment and suppress tumor growth and metastasis. Immunol Rev 2008;222:117-128.

25 Kedinger V, Meulle A, Zounib O, Bonnet ME, Gossart JB, Benoit E, Messmer M, Shankaranarayanan P, Behr JP, Erbacher P, Bolcato-Bellemin AL:Sticky siRNAs targeting survivin and cyclin B1 exert an antitumoral effect on melanoma subcutaneous xenografts and lung metastases. BMC Cancer 2013;13:338.

26 Carew JS, Espitia CM, Zhao W, Mita MM, Mita AC, Nawrocki ST:Targeting Survivin Inhibits Renal Cell Carcinoma Progression and Enhances the Activity of Temsirolimus. Mol Cancer Ther 2015;14:1404-1413.

27 Wagner V, Hose D, Seckinger A, Weiz L, Meißner T, Rème T, Breitkreutz I, Podar K, Ho AD, Goldschmidt H2, Krämer A, Klein B,Raab MS: Preclinical efficacy of sepantronium bromide (YM155) in multiple myeloma is conferred by down regulation of Mcl-1. Oncotarget 2014;5:10237-10250.

28 Zhang L, Zhang W, Wang YF, Liu B, Zhang WF, Zhao YF, Kulkarni AB, Sun ZJ:Dual induction of apoptotic and autophagic cell death by targeting survivin in head neck squamous cell carcinoma. Cell Death Dis 2015;6:e1771.

29 Kumar B, Yadav A, Lang JC, Cipolla MJ, Schmitt AC, Arradaza N, Teknos TN, Kumar P: YM155 reverses cisplatin resistance in head and neck cancer by decreasing cytoplasmic survivin levels. Mol Cancer Ther 2012;11:1988-1998.

30 Gilmore TD. Introduction to NF-kappaB: players, pathways, perspectives. Oncogene 2006;25:6680-6684.

31 Karin M, Lin A: NF-kappaB at the crossroads of life and death. Nat Immunol 2002;3:221-227.

32 Li L, Gondi CS, Dinh DH, Olivero WC, Gujrati M, Rao JS: Transfection with anti-p65 intrabody suppresses invasion and angiogenesis in glioma cells by blocking nuclear factor-kappaB transcriptional activity. Clin Cancer Res 2007;13:2178-2190.

33 Gupta SC, Sundaram C, Reuter S, Aggarwal BB: Inhibiting NF- $\mathrm{BB}$ activation by small molecules as a therapeutic strategy. Biochim Biophys Acta 2010;1799:775-787. 
Cellular Physiology Cell Physiol Biochem 2016;38:2426-2437

\begin{tabular}{l|l} 
and Biochemistry Published online: June 13,2016 & $\begin{array}{l}\text { DO 2016 The Author(s). Published by S. Karger AG, Basel } \\
\text { www.karger.com/cpb }\end{array}$
\end{tabular}

Zhang et al.: Effect of YM155 on Oral Squamous Cell Carcinoma

34 Lee CH, Jeon YT, Kim SH, Song YS: NF-kappaB as a potential molecular target for cancer therapy. Biofactors 2007;29:19-35.

35 Furuta H, Osawa K, Shin M, Ishikawa A, Matsuo K, Khan M, Aoki K, Ohya K, Okamoto M, Tominaga K, Takahashi T, Nakanishi O, Jimi E: Selective inhibition of NF- $\mathrm{BB}$ suppresses bone invasion by oral squamous cell carcinoma in vivo. Int J Cancer 2012;131:E625-635.

36 Song ZB, Ni JS, Wu P, Bao YL, Liu T, Li M, Fan C, Zhang WJ, Sun LG, Huang YX, Li YX: Testes-specific protease 50 promotes cell invasion and metastasis by increasing NF-kappaB-dependent matrix metalloproteinase-9 expression. Cell Death Dis 2015;6:e1703.

37 Tai KY, Shieh YS, Lee CS, Shiah SG, Wu CW: Axl promotes cell invasion by inducing MMP-9 activity through activation of NF-kappaB and Brg-1. Oncogene 2008;27:4044-4055. 